\title{
Evaluation of Policies and Regulations on Plastic Waste Recycling and Its Impact on the Aesthetic of Kaduna Metropolis
}

\author{
Yahya Saleh Ibrahim \\ Centre for Energy \& Environmental Strategy Research (CEESR) \\ Kaduna State University, Kaduna-Nigeria \\ Uba, Halima Abba \\ Kaduna State University (KASU) Geography Department
}

\begin{abstract}
Plastic is increasingly replacing metals, glass, ceramics and wood in many products, Plastic is a waste stream with recycling and recovery potential. The rate of recycling is not keeping up with the rate at which virgin plastics are being produced. The study evaluates the policies and regulations on plastic waste management and the resulting impacts on the environment in Kaduna metropolis. The nominal group technique survey approach was adopted to generate data for the study and analysis. 19 participants were involved in the nominal group discussion. The participants were drawn from various disciplines, profession and strata in both the civil service and citizens. The results show that $68 \%$ of the participants were male and females recorded $32 \%$ of the participants. On whether lack of adequate technical capacity of plastic recycling plants affects collection and disposal of plastic waste in Kaduna metropolis; the result of the NGT ranking showed that the factor of collection capacity challenges was due to lack of technical knowledge of separation at sources. This in a way affects the technical capacity of the few recycling plants in the study area. This aspect was ranked as one of the most impactful factor with a score of 71 points. With regards to impact of policies; the current policies and regulations were considered weak and lame and ranked as a serious factor affecting plastic waste collection, disposal and the aesthetics of Kaduna metropolis with an NGT point score of 84 points. On the impact of recycling, result also showed that the possibility of recycling creating value for the waste thereby making it a resource hence reduction in indiscriminate disposal was considered the most likely major impact plastic waste recycling will bring and was ranked by the stakeholders and got a massive NGT 64 points. The study concludes that plastic waste management in Kaduna metropolis has not advanced as expected. The laws governing plastic waste collection and disposal in the state are weak and enforcement is almost nonexistent. The study recommended new policy guidelines and adequate regulation with capacity for enforcement is required. All stakeholders should be carried along and actively involved in the new policy framework.
\end{abstract}

Keywords: Nominal Group Technique (NGT), Plastic, Waste, Recycling, Aesthetic, Policies

DOI: $10.7176 /$ JEES/11-8-05

Publication date:August $31^{\text {st }} 2021$

\section{Introduction}

Rapid urbanization and the increasing consumption of plastics have resulted in a rapid increase in the generation of plastic waste, making it a major component of the solid waste stream (Oyake - Ombis, 2012). Plastic is increasingly replacing metals, glass, ceramics and wood in many products (Yahya \& Mansur, 2016). Plastic packaging materials are now employed in the food, beverage and other fast moving consumer goods industries (Cooper, 2013). However at their end-of-life circle, plastics present solid waste management challenges (Godfrey, 2019).

The magnitude of plastic use now poses a major waste challenge to city authorities, who are responsible for solid waste management and sanitation especially in African countries where robust waste management systems are lacking, (Yahya, Amina, Fatima \& Sagir, 2019). While many cities in developed countries have made great strides towards instituting effective approaches to waste management that recognize different waste sources, their value, and seek to separate them, (Nas, 2019). Around the world, countries are taking action to minimize these impacts, including banning single-use plastics; changing petroleum-based plastics to alternative products such as paper, glass or biodegradable plastics; and improving waste collection systems to ensure that all wastes are appropriately collected and reprocessed or safely disposed (Godfrey, 2019).

The natural and aesthetic environments in Kaduna metropolis have been affected by the menace of plastic wastes littering the environment blocking drainages and causing flooding. There is the need for a viable, effective, efficient and sustainable policy/regulations that will help in the management of this important waste and resource category in Kaduna state in particular and Nigeria in general (Ugochukwu, Ogbuagu \& Okechukwu, 2014). This among others is the drive for this research as the study seeks to evaluate the policies and regulations on grounds to curb and manage the menace of plastic wastes in Kaduna metropolis as well as the level of plastic recycling and its impact on the aesthetic beauty of the metropolis. 


\subsection{Location}

Kaduna metropolis is located in between latitudes $10^{\circ} 25^{\prime} 15^{\prime \prime} \mathrm{N}$ and $10^{\circ} 36^{\prime} 08^{\prime \prime} \mathrm{N}$ and longitudes $7^{\circ} 23^{\prime} 31^{\prime \prime} \mathrm{E}$ and $7^{\circ} 29^{\prime} 33$ "E (Danjuma, 2015). It is presently the administrative capital of Kaduna state. It covers an estimated area of about $118 \mathrm{~km} 2$ and it covers two main Local Government Areas with some parts of Chikun and Igabi Local Government area. The distance between the Eastern and Western limits of the metropolis is approximately 13.7 $\mathrm{km}$ and between the North and South is approximately $20 \mathrm{~km}$.

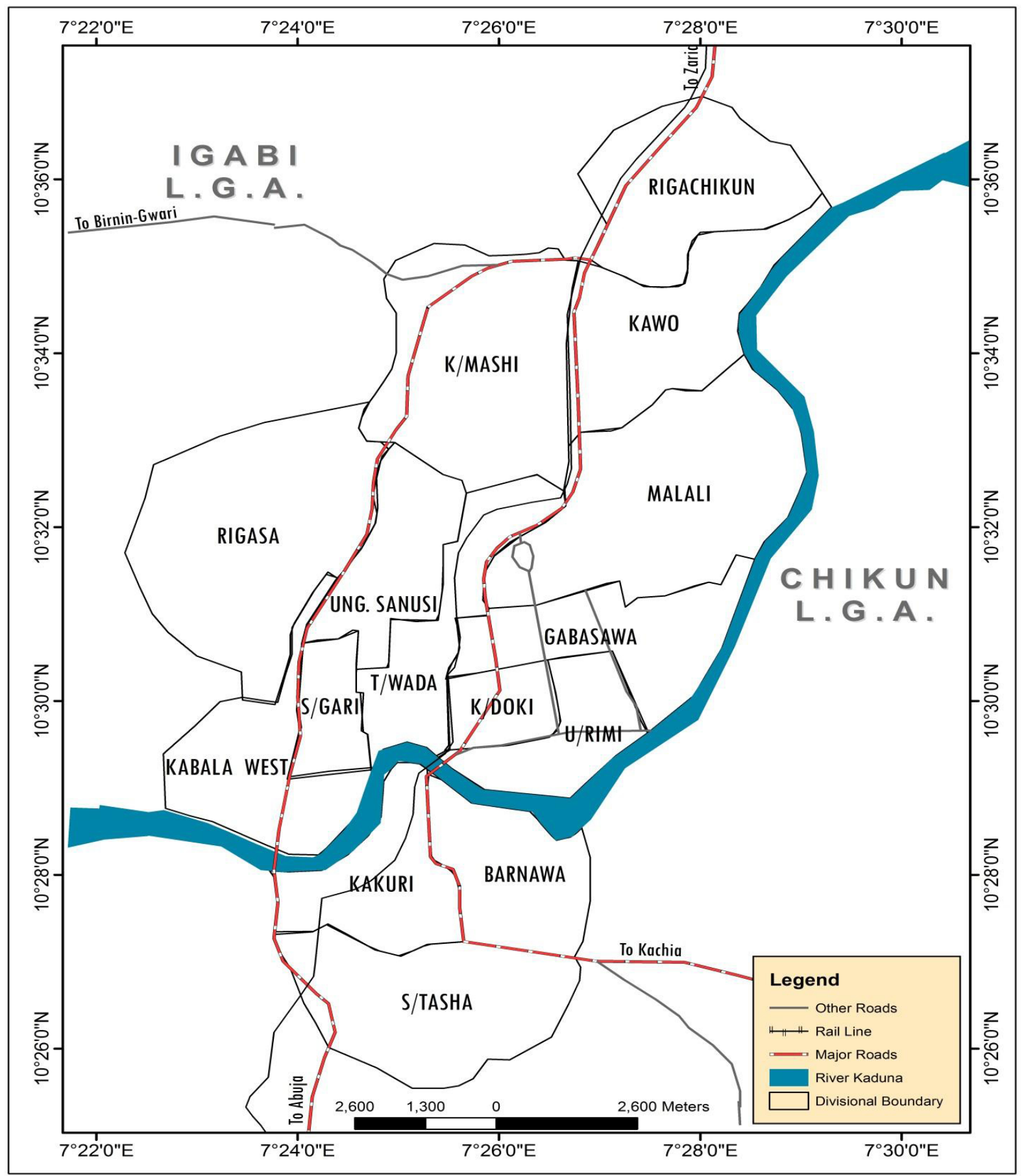

\subsection{Research Design}

This study aimed at evaluating the policies and regulations on plastic waste management and the resulting impacts on the environment in Kaduna metropolis. The study adopts the Nominal Group Technique (NGT). The NGT method was chosen because it promotes the active participation of all group members to produce new ideas through a brain storming format. The study followed a classic NGT technique including:

i. Silent generation of responses to a particular question 
ii. Round-robin sharing and recording of ideas

iii. Group discussion for clarification

iv. Voting on items, with respect to importance, or relatedness

3.1.1 Types and Sources of Data

The types of data for this study are information on the plastic waste generation, management, recycling, existing policies and regulations as well as policy and regulation gaps in plastic waste control and management and its impact on the aesthetic of the environment of Kaduna metropolis. The main sources of the data were primary data which were obtained through the nominal group discussions, voting and ranking of independent participant's opinion. Data sources also included oral interviews with plastic manufacturers and users as well as staff and management of KEPA and field observations. Secondary information was also obtained from journals, textbooks and other documented materials to aid the interpretation of findings.

3.1.2 Data Collection

The data collection tool for this study was through the nominal group discussions which provided answers to the research questions in this study. The data was collected in form of responses and opinions of participants

3.1.3 Data Analysis

Data generated was analyzed both quantitatively and qualitatively using descriptive analysis, frequencies and tables were also used in the analysis.

\subsection{Result and Discussion}

Plastic waste has been found to constitute environmental eye sores in many places where research has been carried out in this study. Due to its poor biodegradability; it tends to linger around for a reasonable time and littered by water, wind and scattered along the streets, drainages, ponds, flowers and around buildings (Godfrey, 2019). Table 4.2 shows the rankings done by participants at the nominal group discussions to determine the extent of plastic waste impact on Kaduna metropolitan aesthetics.

Table 1. Shows the results of indiscriminate wastes disposal in Kaduna metropolis. Indiscriminate plastic waste disposal has been an issue in the last decade in Kaduna and many Nigerian cities. The current pattern in which plastic materials are been used and discarded in Kaduna metropolis fails to capture any economic benefit but rather harms both the natural and the aesthetic of the environment. Table 1 shows the rankings of the five major factors outlined by key stakeholders in environmental and waste management policies during the nominal group discussion to assess the impact of technical capacity to handle recycling and its effect.

Table 2. shows the ranking of factors relating to technical capacity impact on collection and disposal of plastic waste in Kaduna metropolis results. The result reveals the most impactful factor to the least impactful factor based on their point score. The result shows that collection capacity challenges due to lack of waste separation is ranked as the major technical factor with 71 points. Previous researches have highlighted the challenges associated with waste segregation in developing economies. Yahya et al., (2019) had affirmed that, lack of source separation of solid wastes in Nigeria results in a larger fraction of waste plastic and other polymers ending up at dumpsites together with other disposed wastes and in some cases they are burnt thereby polluting the environment as they have been mixed and can no longer be separated. 

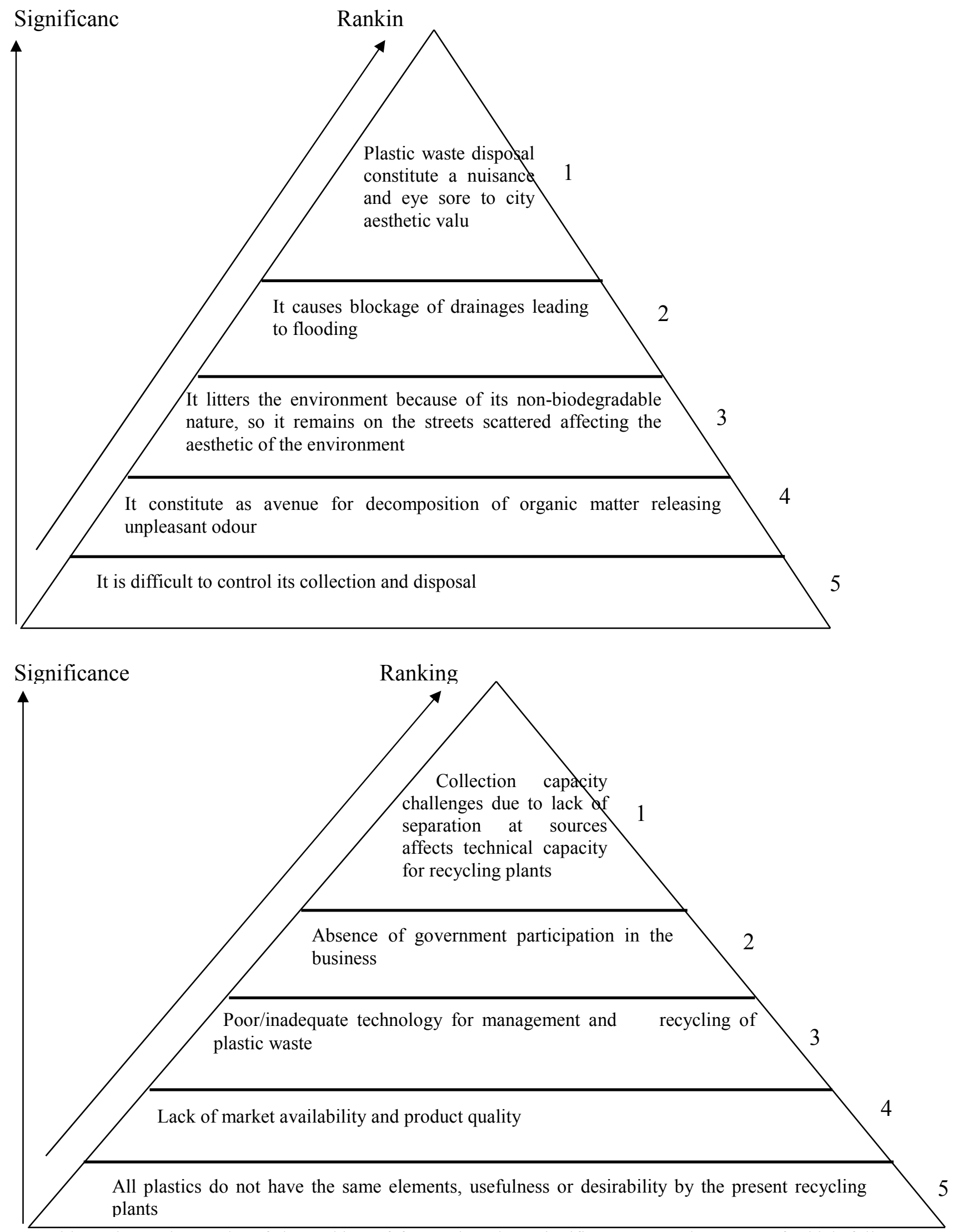

Table 3 shows the results of the ranking of factors based on significance as to the extent of which full plastic recycling could impact on the aesthetics and sanitary conditions of Kaduna metropolis. Result in Table 3 ranked the possibility that recycling creates value for the waste thereby making it a resource hence reduction in 
indiscriminate disposal as one of the most important among the factors with 67 points. This factor is considered the most impactful among the five factors; this is because research in other parts of the world has shown that recycling reduces the quantity of waste by making plastic waste a commodity that is needed for the production of other items (raw material). Creating value for plastic wastes as a most sought after material with economic value, thereby encouraging users and scavengers to go in search of it.

\subsection{Discussion}

Result from the study shows that a total of 19 participants were involved in the nominal group discussion and $68 \%$ of them were male and females with $32 \%$. On the extent of plastic waste affecting the aesthetics of Kaduna metropolis; result obtained indicates that among the five factors that were put forward, the factor on plastic waste disposal constituting nuisance and eye sore to the city aesthetic was ranked the most impactful factor and received a point score of 68 points. Difficulty in controlling plastic waste collection and disposal was ranked fifth in terms of impact and got a score point of 31 points. The implication here is that the impact of plastic waste constituting nuisance and eyesore will impact the aesthetic environment of Kaduna metropolis more than the challenges of controlling plastic waste collection and disposal.

With regards to the five (5) factors that determines the extent to which the technical capacity of plastic recycling plants affects collection and disposal of plastic waste in Kaduna metropolis; the result of the ranking showed that the factor of collection capacity challenges due to lack of separation at sources affects the technical capacity of the few recycling plants was ranked as the number one most impactful factor with a score of 71 points. The result also showed that absence of government participation in the business of plastic waste recycling was ranked second with 65 points while the diversity of plastic waste elements, usefulness or desirability by the present recycling plants was ranked $5^{\text {th }}$ which is the least with 47 points. Recycling plastic waste is not without challenges, except the most crucial factors identified are address; achieving meaningful success will be a herculean task.

Plastic waste policies and regulations impact on collection, disposal and aesthetics in Kaduna metropolis as a key objective of this study had five factors of significance that defines its impacts. Results showed that the current policies and regulations were considered weak and lame and ranked as the number one factor affecting plastic waste collection, disposal and the aesthetics of Kaduna metropolis with a point score of 84 points, thus highlighting its significance in any attempt going forward. The factor with lowest ranking had 39 points and was ranked fifth; this was the impact of regulatory synergy bringing plastic production, usage, monitoring and enforcement on a collaborative platform. This means that while there is the need for active and strong policies and regulation to improve on plastic waste management in the state, major emphasis should be on ensuring that the policies are strong and encompassing with enforcement capacity and capabilities.

Measuring the impact of plastic waste recycling on the aesthetics and sanitary conditions of Kaduna metropolis, the possibility of recycling creating value for the waste thereby making it a resource hence reduction in indiscriminate disposal was considered the most likely major impact plastic waste recycling will bring and was ranked number one by the stakeholders and got a massive 64 points. Reducing the risk of contamination was considered the least of the possible gains of full scale plastic waste recycling and was ranked fifth.

Recycling of plastic waste will be of great importance to the aesthetics and development of Kaduna metropolis owing to its significance, but a vibrant policy and regulation that can be enforced to the latter is required.

\subsection{CONCLUSION}

This study evaluates policies and regulations on plastic waste management and the resulting impacts on the environment in Kaduna metropolis with emphasis on identifying the extent to which policies and regulations governing plastic wastes management in Kaduna state affect collection, disposal and aesthetics of the metropolis. The study adopted the Nominal Group Technique discussion that had 19 participants in attendance. Each of the four research objectives had five factors that were narrowed from the pool of factors that had been generated by the respondents. Each group of five factors were ranked using score points from first to fifth based on assumed significance and possible impacts. The major challenge associated with weak policy and regulation on plastic waste in Kaduna is that the poor manner in which plastic waste disposal is handled constitutes nuisance and eye sore to the city aesthetic as shown by the rankings. Plastic waste collection capacity, collection challenges due to lack of separation at sources have major impact and effect on the technical capacity of the few recycling plants currently operating in Kaduna. This should be a major source of concern to policy makers and stakeholders as efforts are made towards developing and implementing plastic waste recycling policies and regulation.

The current laws governing plastic wastes handling in Kaduna State are considered weak and lame and do not have the capacity to guarantee any reasonable degree of success. The laws have not been able to properly address plastic waste collection and disposal, hence the negative impacts is seen on the aesthetics of Kaduna metropolis. The study discovered that recycling will create value on plastic waste by making it a resource, hence 
reduction in indiscriminate disposal which will improve the sanitary conditions of the urban environment.

The study therefore concludes that plastic waste management in Kaduna metropolis has not advanced as expected. The laws governing plastic waste collection and disposal in the state are weak and enforcement is almost nonexistent. Recycling will go a long way to improve plastic waste management as well as the sanitary conditions of the metropolis if government will take the center stage and create the enabling environment and support.

\subsubsection{Recommendations}

The study therefore recommends that;

i. Current policies and regulations are ineffective, new policy guidelines and adequate regulation with capacity for enforcement is required.

ii. All stakeholders should be carried along and actively involved in the new policy framework.

iii. Regulatory bodies need to be properly funded with right staff and technology as seen in other developed countries to be able to ensure adequate compliance and prosecution of offenders without delay.

iv. Recycling should be fully adopted and promoted in Kaduna state with the government taking a centre stage in the business.

V. Technological support and incentives should be given to recycling companies already operating in the state to encourage and attract more investors to lift the sector and create wealth and employment.

vi. New strategies should be formulated by the regulatory agencies to address the sales of plastic products to the public; No business should be allowed to offer for free plastic

vii. There should be declaration of "Go Green Policy" once in a month, this policy will declare plastic usage in shops, market, wet markets and other areas where plastics bags are used in multiple number restricted to only "one bag" no matter the purchase. If extra plastic is needed "environmental distress fee" on the extra must be charge

\section{References}

Afon, A. O., Alwadood, J. A. (2016). The Growth of Kaduna Metropolis between 1973 and 2012: The Physical Planning Implications, International Journal of Scientific and Technology Research, 5 (3): 7-13

Allam, Z. and Jones, D.S. (2018). Towards a Circular Economy: A Case Study of Waste Conversion into Housing Units in Cotonou, Benin, Urban Science, 2, (118): 1-19

Al-Salem, S.M., Lettieri, P. and Baeyens, J. (2010). The Valorization of Plastic Solid Waste (PSW) by Primary to Quaternary Routes: From Re-use to Energy and Chemicals, Prog. Energy Combust. Sci., 36(1): 103-129

Apriantis, E. (2017). A Huge Number of Artificial Waste Material can be Supplementary Cementitious Material (SCM) for Concrete Production-A Review Part II, J. Clean. Prod., 142: 4178-4194

Babayemi, J., Ogundiran, M., Osibanjo, O. (2017). Current Levels and Management of Solid Wastes in Nigeria, Environmental Quality Management, 26(3): 29-53.

Babayemi, J.O., Sindiku, O., Osibanjo, O. and Weber R. (2015). Substance Flow Analysis of Polybrominated Diphenyl Ethers in Plastic from EEE/WEEE In Nigeria in the Frame of Stockholm Convention as a Basis for Policy Advice, Environ Sci Pollut Res Int, 22(19):14502-14

Babayemi, J.O., Ogundiran, M.B., Weber, R. and Osibanjo, O. (2018). Initial Inventory of Plastics Imports in Nigeria as a Basis for More Sustainable Management Policies, Journal of Health and Pollution, 8 (18): 116

Bahri, G. (2005). Sustainable Management of Plastic Bag Waste:The Case of Nairobi, Kenya, MSc Thesis, Department of Environmental Management and Policy, Lund, Sweden,

Bai, R., Sutanto, M. (2002). The Practice and Challenges of Solid Waste Management in Singapore, Waste Management, 22:557-567.

Beccarello, M., Foggia, G.D. (2016). Moving Towards a Circular Economy, Economic Impacts of Higher Material Recycling Targets, Mater, Today Proceedings, 5: 531-543

Boddy, C. (2012). The Nominal Group Technique: An Aid to Brainstorming Ideas in Research, Qualitative Market Research: An International Journal, 15: 6-18

Brooks, A. L., Wang, S., and Jambeck, J. R. (2018). The Chinese Import Ban and its Impact on Global Plastic Waste Trade, Science Advances, 4(6): 01-31

Brouwer, M.T.; van Velzen, T.; Augustinus, A.; Soethoudt, H.; De Meester, S.; Ragaert, K. (2017). Predictive model for the Dutch post-consumer plastic packaging recycling system and implications for the circular economy, Waste Management, 71, 62-85

Carey, C., Phelan, W., Boland, C. (2007). Organic Waste Management in Apartments: Final Report; Environmental Protection Agency: Wexford, Ireland

Cooper, T.A. (2013). Developments in Plastic Materials and Recycling Systems for Packaging Food, Beverages 
and Other Fast-Moving Consumer Goods, In: Farmer N, Editor. Trends in Packaging Of Food, Beverages And Other Fast-Moving Consumer Goods, Sawston, UK: Woodhead Publishing

Dakwale, A.V. and Ralegaonkar, R.V. (2014). Development of Sustainable Construction Material using Construction and Demolition Waste, Indian J. Eng. Mater. Sci., 21: 451-457

Danjuma, E.S. (2015) Infant and Child Mortality Differentials in Chikun Local Government Area, Kaduna State. Unpublished Thesis Submitted to the School Of Postgraduate Studies, Ahmadu Bello University, ZariaNigeria.

Ellen MacArthur Foundation. (2016). The New Plastics Economy: Rethinking the Future of Plastics, Report produced by World Economic Forum and Ellen MacArthur Foundation

European Commission. (2018). Communication from the Commission to the European Parliament, the Council, the European Economic and Social Committee and the Committee of the Regions - A European Strategy for Plastics in a Circular Economy, Brussels, January 16, 2018 COM (2018) 28 Final

Esposito, M., Tse, T. and Soufani, K. (2017). Is the Circular Economy a New Fast-expanding Market?, Thunderbird International Business .Review., 59:9-14.

Gandenberger, C., Orzanna, R., Klingenfuß, S.and Sartorius, C. (2014). The Impact of Policy Interactions on the Recycling of Plastic Packaging Waste in Germany, Working Paper Sustainability and Innovation, No. S8/2014, Fraunhofer ISI, Karlsruhe

Garcia, J.M. (2016). Catalyst: Design Challenges for the Future of Plastics Recycling, Chem, 6(1):813-815.

Gowono, J.E. (2019). Assessment of Municipal Solid Waste Management in Jimeta, Yola North Local Government Adamawa State, Nigeria, Unpublished MSc Thesis, Department of Geography, Nigerian Defence Academy, Kaduna

Gregory, M.R., (2009). Environmental Implications of Plastic Debris in Marine Settings-Entanglement, Ingestion, Smothering, Hangers-on, Hitch-hiking and Alien Invasions, Phil. Trans. R. Soc. B, 364: 20132025

Gwada, B.; Ogendi, G.; Makindi, S.M.; Trott, S., (2019). Composition of Plastic Waste Discarded by Households and its Management Approaches, Global J. Environ. Sci. Manage., 5(1): 83-94

Gopinath, A., Bahurudeen, A., Appari, S. and Nanthagopalan, P. (2018). A Circular Framework for the Valorization of Sugar Industry Wastes: Review on the Industrial Symbiosis between Sugar, Construction and Energy Industries, Journal of Cleaner Production, 203: 89-108

Harvey, N., and Holmes, C. A. (2012). Nominal Group Technique: An Effective Method for Obtaining Group Consensus, International Journal of Nursing Practice, 18: 188-194.

Hopewell, J., Dvorak, R. and Kosior, E. (2009). Plastics Recycling: Challenges and Opportunities, Philosophical Transactions of the Royal Society, 364: 2115-21226

Industrial Innovation and Environmental Regulation (2007)

Jambeck, J. R., Geyer, R., Wilcox, C., Siegler, T. R., Perryman, M., Andrady, A., ... Law, K. L. (2015). Plastic Waste Inputs from Land into the Ocean, Science, 347(6223), 768-771

Kirchherr, J.; Reike, D.; Hekkert, M. (2017). Conceptualizing the Circular Economy: An analysis of 114 Definitions, Resource Conservation and Recycling, 127: 221-232

Kobza, N., Schuster, A. (2016). Building a Responsible Europe: The Value of the Circular Economy, IFACPapersonline, 49: 111-116

Kunwar, B., Cheng H.N., Chandrashekaran, S.R., Sharma, B.K. (2016). Plastics to Fuel: A Review, Renew. Sust. Energ. Rev,. 54, 421-428

Koushal, V., Sharma, R., Sharma, M., Sharma, R., and Sharma, V. (2014). Plastics: Issues Challenges and Remediation, International Journal of Waste Resources, 4: 134-140

Max Lock and partners (1967): Kaduna Master Plan: A Survey and Plan of the Capital Territory for the Government of the northern Nigeria. London.

MLS (2018). The Declaration of the Global Plastics Association for solutions on Marine Litters, 4th Progress Report, Marine Litter Solutions

Mohammed H. (2013): People and Politics; A (Brief) History of Kaduna the City of Crocodiles. www.gamji.com/haruna/haruna251.htm. Retrieved on 12 May 2013

Muhammad, A.M. (2018). Public Acceptance of a Proposed Ban on Plastic Bags in Nigeria: The Case of YolaJimeta, Adamawa State, Unpublished BSc Thesis, Department of Natural and Environmental Sciences, American University of Nigeria, Yola

Mutha, N.H., Patel, M. and Premnath, V. (2006). Plastics Materials Flow Analysis for India, Resource Conservation and Recycling, 47:222-244

Nielsen, T.D., Haselbalch, J., Holmberg, K. and Stripple, J. (2019). Politics and the Plastic Crisis: A Review throughout the Plastic Life Cycle

Office of Appropriate Technology (1981). Alternatives to the Land Disposal of Hazardous Wastes: an Assessment for California, Google Scholar 
Oyake-Ombis, L., van Vliet, B. J., and Mol, A. P. (2015). Managing Plastic Waste in East Africa: Niche Innovations in Plastic Production and Solid Waste, Habitat International, 48: 188-197.

Onwughara, I. N., Chukwu, H. C., Alaekwe, O. I. and Lackson, A. (2013). Focus on Potential Environmental Issues on Plastic World towards a Sustainable Plastic Recycling in Developing Countries, International Journal of Industrial Chemistry, 4(34): 1-13

Orset, C., Barret, N., Lemaire, A. (2017). How Consumers of Plastic Water Bottles are Responding to Environmental Policies? Waste Management, 61: 13-27

Oyake-Ombis, L. (2012). Managing Plastic Waste in Urban Kenya: Niche Innovations in Production and Recycling, PhD Thesis, Wageningen University, Wageningen, NL

Panda, A.K., Singh, R.K. and Mishra, D.K. (2010). Thermolysis of Waste Plastics to Liquid Fuel: A Suitable Method for Plastic Waste Management and Manufacture of Value Added Products-A World Prospective, Renew Sustain Energy Rev., 14:233-48.

Salami, L., Susu, A., Patinvoh, R. and Olafadehan, O. (2011). Characterisation Study of Solid Wastes: A Case of Lagos State, International Journal of Applied Science and Technology, 1(3): 23-32

Suocheng D, Tong KW, Yuping W. (2001). Municipal solid Waste Management in China: Using Commercial Management to Solve a Growing Problem, Utilit Policy, 10:7-11

Sridhar, M.K.C., Oluborode, J.A. and Zacchaeus, U. (2017). Waste management policy and Implementation in Nigeria, National Journal of Advanced Research, 3 (3): 23-35

Ugochukwu, Sc., Ogbuagu, G. and Okechukwu, F. (2014). An Appraisal of the Sources, Quantities and Prices of Imported Building Materials in Nigeria, International Journal of Advanced Research, 2(9): 871-8

UNEP (2007). Environmental Pollution and Impacts on Public Health: Implications of the Dandora Municipal Dumping Site in Nairobi

Yahya S.I. and Mansur, M.S. (2016). Assessment of E-Waste and Plastics in Kaduna Nigeria, Paper presented at the Acdemic Staff Union Conference, Organized by ASUP, Hassan Usman Katsina Polytechnic Katsina, 2016.

Yahya S.I., Aminat, Y., Fatimah, Y.K. and Sagir, M.H. (2019). Medical Wastes Management In Primary Health Care (Phc) Centers in Sabon Gari, Journal of Remote Sensing, Science and Energy Management, 4 (5): 2139

\section{APPENDIX}

Table 1: To what extend does the status of plastic waste in Kaduna affect its aesthetics

\section{Factors}

Plastic waste disposal constitute a nuisance and eye sore to city aesthetic value

It causes blockage of drainages leading to flooding

It litters the environment because of its non-biodegradable nature, so it remains on the streets scattered affecting the aesthetic of the environment

It constitute as avenue for decomposition of organic matter releasing unpleasant odour

It is difficult to control its collection and disposal

\begin{tabular}{|c|c|}
\hline Total Score & Ranking \\
\hline 68 & 1 \\
\hline 54 & 2 \\
\hline 50 & 3 \\
\hline 42 & 4 \\
\hline 31 & 5 \\
\hline
\end{tabular}

Table 3: Extent which the level of plastic wastes recycling in Kaduna metropolis contribute to its aesthetics and sanitary condition

\section{Factors}

Recycling create value for the waste thereby making it a resource hence reduction in indiscriminate disposal

There will be free flow of storm water during the rainy seasons leading to less

flooding in the city.

Less litters on our streets and parks

More revenue and investment, reduce importation of plastic raw materials

Reduce the risk of contamination and disease outbreak; through effective waste disposal

Source: Nominal Group Discussion, 2020

$\begin{array}{ll}\frac{\text { Total Score }}{\underline{\text { Points }}} & \text { Ranking } \\ 67 & 1 \\ 50 & 2 \\ 42 & 3 \\ 41 & 4 \\ 37 & 5\end{array}$

